\title{
Language Policy in the KMT and DPP eras
}

\section{Henning Klöter}

\section{OpenEdition}

\section{Journals}

\section{Electronic version}

URL: http://journals.openedition.org/chinaperspectives/442

DOI: 10.4000/chinaperspectives.442

ISSN: 1996-4617

\section{Publisher}

Centre d'étude français sur la Chine contemporaine

\section{Printed version}

Date of publication: 1 December 2004

ISSN: 2070-3449

\section{Electronic reference}

Henning Klöter, «Language Policy in the KMT and DPP eras », China Perspectives [Online], 56 | november - december 2004, Online since 29 December 2008, connection on 28 October 2019. URL : http://journals.openedition.org/chinaperspectives/442; DOI : 10.4000/chinaperspectives.442

This text was automatically generated on 28 October 2019

(c) All rights reserved 


\title{
Language Policy in the KMT and DPP eras
}

\author{
Henning Klöter
}

1 It is one of the paradoxes of any analysis of Taiwan's linguistic issues that the most widely spoken language lacks an established name. The name Taiyu, literally "the language(s) of Taiwan, Taiwanese" is often used as a collective term for the group of Southern Min dialects spoken by about $73 \%$ of Taiwan's present-day population. Other terms for the same language include Hoklo (also spelled Holo; the etymology of these terms is uncertain), Taiwanese Min, and Taiwanese Hokkien. Hokkien reflects the Southern Min expression Hok-kien for Fujian.

2 Its frequent use notwithstanding, the term Taiyu/Taiwanese has also been criticised as it suggests that Southern Min is the only local language of Taiwan. This is by no means the case. Other languages spoken in Taiwan are Mandarin Chinese-the official language-, Hakka (spoken by $12 \%$ of the population), and 12 Austronesian languages spoken by the indigenous population in central Taiwan and along the east coast. Speakers of Hakka dialects traditionally live in Xinzhu and Miaoli counties in northwestern Taiwan, where they account for about $60 \%$ of the population ${ }^{1}$. In bigger cities, Hakka speakers constitute a minority.

3 Today it is not uncommon for younger speakers in Taiwan to be equally fluent in Taiwanese and Mandarin. The Taiwanese spoken by young persons is often regarded as impure and strongly Mandarinised by older Taiwanese speakers. Most speakers of Hakka dialects also have high fluency in Mandarin and often a good command of Taiwanese. The same applies to speakers of Austronesian languages. The influx of Chinese immigrants over the last four centuries has drastically reduced the proportion of the indigenous population, which is now $1.7 \%$ of the entire population. In the past two centuries, about a dozen Austronesian languages have become extinct, and the remaining 12 languages are threatened with extinction' ${ }^{2}$.

4 For stylistic reasons it seems reasonable to prefer the benefits of the term "Taiwanese" to the political correctness of cumbersome alternatives. I will use "Taiyu" instead of "Taiwanese" only when unambiguous reference to Taiwanese as a linguistic variety is 
required, e.g., when Taiwanese literature, meaning literature produced in Taiwan, needs to be distinguished from Taiyu literature, i.e., literature in the Taiwanese language.

5 In 1945, Taiwan ceased to be a Japanese colony and became a province of the Republic of China (ROC). Since then, the official treatment of local languages has shifted from systematic oppression to toleration and, since the 1990s, modest inclusion in the school curriculum. At the beginning of its rule in Taiwan, the ruling Kuomintang (KMT) reiterated its view that linguistic diversity was a factor impeding the country's unity. In the China Handbook of 1951, linguistic issues receive little attention: "China has only one written language. The spoken language, however, consists of various dialects. In recent years the National Spoken Language Movement has made considerable progress in overcoming the difficulties caused by these dialects" 3 .

6 More than 50 years later, many things have changed. The KMT is no longer the ruling party, and the name of the official annual overview has been changed from the former China Handbook into the Taiwan Yearbook. In the latest edition of the Yearbook, the passage on languages likewise contrasts sharply from the above quotation: "Taiwan society is a rich mixture of diverse cultures, and more people are becoming aware of the importance of preserving various languages and dialects. This awareness has been the propelling force behind government efforts to promote nativist education (xiangtu jiaoyu). Starting in September 2001, primary school students throughout Taiwan have been required to take at least one local language course. For junior high school students, however, such language courses remain an elective. The government supports such courses with various levels of funding, which is used to compile teaching materials, publish teacher handbooks, hold teacher workshops, produce audio and video cassettes"4.

7 It would be tempting to attribute this about-face in language policy to the regime change in the presidential office of 2000, when for the first time in Taiwan's post-war history the KMT lost power to the Democratic Progressive Party (DPP) and its candidate Chen Shui-bian. Chen had, after all, during the campaign, wrapped his Taiwan-centred political agenda in a strong pro-Taiwanese rhetoric, both ideologically and linguistically. By frequently addressing his electorate in Taiyu, he had succeeded in presenting himself as a representative of a genuine Taiwanese identity. And there is little doubt that the regime change of 2000 has led to some changes in the government's language policy. However, as I argue in this paper, it would be oversimplifying to view the turnaround from oppression to promotion of Taiyu in blue (KMT) and green (DPP) terms only. Important changes in the policy towards Taiyu had rather already been introduced during the 1980s. But they were not primarily the result of a paradigm change on the part of the government, rather being brought about by non-governmental language revivalist groups. Neither the KMT nor the DPP governments have thus far fully embraced the agenda of the revivalists. Lacking substantiality, changes achieved so far have above all a symbolic value.

Historical overview From oppression to toleration: 1949-1979

8 For several years after 1945, the ROC administration tried to adjust its language policy to Taiwan's linguistic reality. According to Feifel, "[i]n an attempt to resinify the population, the Nationalist government ran a programme to encourage the use of Minnan hua [i.e., Taiyu] in Taiwan, but this was regarded as a first step toward the acquisition of Mandarin by the local people. A phonetic script for Minnan hua was 
adopted and promoted for this purpose"5. In the late 1940s, the withdrawal of the Nationalist government to Taiwan led to a new wave of immigration from the mainland and to drastic linguistic changes.

9 After the mid-1950s, the KMT government began severely restricting the use of local languages in public settings. The exclusive use of Mandarin was enforced on the grounds that Taiwan was a province of China and that Mandarin represented the national language of China. In Robert Cheng's words, to survive as the legitimate government of the whole of China, the ROC government had to maintain Mandarin as the national language. Furthermore, as Mandarin speakers were in the minority, the government had to take steps "to maintain the status of Mandarin against the natural tendency of Mandarin speakers to be assimilated into the Taiwanese majority" .

10 Following these considerations, the government began severely restricting the use of local languages in public settings after the 1950s. According to Feifel, "[t]he more benign attitude which the government had shown towards Minnan hua in the past was replaced by active hostility. From this time on schooling was conducted solely in Mandarin and the use of any other language variety was punished"7. The oppression of local languages followed a series of language laws and decrees issued between 1950 and 1980. For instance, in 1956 the KMT government officially restricted the use of dialects in schools. Schools set up disciplinary patrols (jiuchadui) which controlled that the law was respected ${ }^{8}$. One year later, an official decree ruled that missionaries were no longer allowed to preach in a dialect. The Broadcast and Television Law of 1976 limited the use of languages other than Mandarin in television and radio broadcasts.

11 This active promotion of Mandarin has produced a generation of multilinguals. Hence, Mandarin evolved as the main language of government, education and the media. It also serves as a lingua franca among mainland immigrants who arrived after 1945, commonly referred to as waisheng ren (literally "people from outside provinces". These immigrants were in most cases speakers of different Chinese dialects, for instance Cantonese, Hunanese and Shanghainese. Nowadays these dialects are hardly used'

From toleration to cultivation: 1979-2004

12 The about-face from the former oppression of Taiyu and other local Taiwanese languages was made after the late 1970s, when Taiwan's political landscape changed drastically. Following its gradual international isolation, the island entered a period of political liberalisation and democratisation. In the same period, calls for Taiwan's political separation from China intensified. A conception of Taiwan's distinctiveness has meanwhile expanded beyond the political arena and it now dominates literary, linguistic, and historical discourses.

13 It was after the arrest of leading opposition figures in the aftermath of the Kaohsiung Incident in 1979 that cultural debates discovered the Taiwaneseness of Taiwan. In the aftermath of the protest, leading members of the opposition were sentenced to long prison terms. Political decision-making gradually adapted to the new intellectual and social trends. Laws and regulations prohibiting the use of local languages in public settings were gradually lifted. In November 1987, for instance, the three governmentcontrolled television stations started to broadcast news in Taiwanese. In parliament, the use of Mandarin was taken for granted without official regulation until the late 1980s. When the legislator Zhu Gaozheng used Taiyu during a parliamentary debate in March 1987, he provoked a substantial scandal. In the meantime, Taiwanese has 
become a fully-accepted language of the legislature and the dominant language in electoral campaigns.

In 1990, Yilan County became the first county to offer elective Taiyu language courses in elementary and junior high schools. In the following years, similar programs were initiated in other counties and also included courses for Hakka and Austronesian languages. In 1993, the Interior Ministry conceded that the repressive language policy of the past had been a mistake ${ }^{10}$. Since then, the "assimilationist [language] policy has been replaced with strong support for multiculturalism and official respect for, even nurturing of, aboriginal [i.e., Austronesian] languages and other minority languages" 11 . In late 1999, the then Minister of Education, Yang Chaur-shiang, proclaimed the inclusion of "local culture education" in the elementary and junior high school curriculum. He furthermore announced that, "in the future [...] as a part of the new [...] curriculum, indigenous languages will be listed as a required subject for third grade students and above. Other indigenous culture teaching activities will be integrated into various domains of learning"12.

Taiwan-centred political reforms were intensified after the victory of the DPP in the presidential elections of 2000. In 2001, nativist education was declared a compulsory subject at elementary schools. In principle, the programme includes language courses in one local language, i.e., Taiwanese, Hakka, or an Austronesian language. Due to a lack of teachers and other resources, most schools offer Taiwanese classes only. One year later, a language equality law was drafted. It aims at creating legal foundations for equal treatment of all Taiwanese languages and contains guidelines for the standardisation of Taiyu, Hakka and Austronesian languages as well as their role in education ${ }^{13}$.

The architects of changeGovernmental and non-governmental language planners

Changing the status of a language in a society follows political decisions and a complex set of preparatory language planning measures. In the preceding paragraphs, the changing status of Taiwanese has been described as a consequence of political decisionmaking from above. On an official level, new language laws and decrees have chiefly been formulated by two institutions under the Ministry of Education: the Department of Elementary and Junior High School Education (Guomin jiaoyu si, hereafter: DEJ) and the National Languages Committee (Guoyu tuidong weiyuanhui, hereafter: NLC; significantly, its official English translation has been changed from the former "Mandarin Promotion Council"). The DEJ devises the guidelines for mother tongue education at primary and secondary schools, while the NLC formulates linguistic standards.

However, language planning measures can be but are not necessarily taken by government agencies. According to Cooper, "[l]anguage planning may be initiated at any level of a social hierarchy, but it is unlikely to succeed unless it is embraced and promoted by elites and counter-elites. [...] Neither elites nor counter-elites are likely to embrace the language planning initiatives of others unless they perceive it in their own interest to do so" ${ }^{14}$. From this perspective, the post 1979-period can best be described as the governmental embracement of non-governmental language planning.

Non-governmental planning: the case of written Taiwanese

18 Arguably the most prominent example for non-governmental language planning is the development of a written norm for Taiyu. In the 1960s and 1970s, debates on written Taiwanese had been impeded by the rigorous promotion of Mandarin. As A-chin Hsiau 
points out, "postwar debates on literature [...] barely addressed the linguistic issue, because the use of Mandarin was taken for granted" 15 . Although this period "did witness the cultural elite's lively interest in, and enthusiastic inquiry into, local social life and cultural resources," such trends were "far from a 'Taiwanese consciousness' with explicit political implications" ${ }^{16}$. This changed during the 1980s, when various literary writers, lexicographers, and language revivalists started to engage in developing a Taiyu orthography and promoting written Taiwanese. After the late 1990s, various language revivalist organisations were founded. According to Hsiau, these nongovernmental groups "were created for the purpose of reviving native languages, devising Hoklo (Taiyu) vernacular writing systems, and promoting Hoklo literature" ${ }^{17}$. In 2004, a number of Taiyu revivalist groups set up parent organisation jointly set up the Global Coalition for Taiwanese Mother Languages (Shijie Taiwan muyu lianmeng). The major political goal of this parent organisation is the elevation of the legal status of all Taiwanese languages ${ }^{18}$.

19 The proposed orthographies make use of a variety of scripts. Typologically, these scripts can be divided into the Chinese character script, alphabetic orthographies, phonetic symbols, and mixed scripts. Whereas all these orthographies have important philological dimensions, answers to questions on the diversity of written Taiwanese lie outside the realm of grapheme-morpheme relations ${ }^{19}$. Instead, they are to be sought in the changing ideological patterns which have emerged from Taiwan's tumultuous past. For the sake of brevity, the following paragraphs are restricted to the character-based and alphabetic orthographies.

Character-based scripts for Taiwanese are largely to be found in Taiyu fiction and dictionaries. Taiwanese dialect poems (fangyan shi) were an important input for the postwar debate on written Taiwanese. In the 1970s, literary experimentation in the local vernacular was initiated by Lin Zongyuan who in turn inspired the younger poet Xiang Yang ${ }^{20}$. This new generation of dialect poets was originally not driven by any political motivations. However, the new theoretical debate on genuine Taiwanese literature and the establishment of a Taiwanese orthography soon became closely linked to the socio-political and cultural movement against the "Greater China" policy of the KMT government.

21 Today, the number of authors writing in Taiwanese has increased considerably. Whereas pioneering collections of prose or poetry were initially often published at the author's own expense, recognised publishing houses now include various genres of dialect literature in their programme. The Taipei-based Qianwei Chubanshe (Vanguard Publishing House) for instance, has regularly published series of Taiyu literature. The recognition of Taiyu literature by commercial publishers, however, has not contributed to orthographic standardisation, as the publishing houses do not have internal standards for the writing of Taiwanese ${ }^{21}$.

Recognised and up-and-coming young writers also publish in literary journals exclusively devoted to the promotion of written Taiwanese. One of the first major journals in and about the Taiwanese language- the Tai-Bun Thong-Sin (Taiwanese Writing Forum)-has been published in the United States since 1991. Among major magazines presently published in Taiwan we find La-cing (Sowing seeds) and Tai-bun bong-po (Casual reports on written Taiwanese). The former was first published in 1995, the latter one year later. The editions contain announcements, short stories, poems, and historical anecdotes. 
23 Taiwanese lexicography has likewise developed quickly in the last two decades. Without exception, Taiyu dictionaries published during the 1990s result from the private efforts of single authors ${ }^{22}$. Lacking official authorisation and general acceptance, particular spellings of such dictionaries have remained individual suggestions for written Taiwanese rather than a normative codification. The authors generally adhere to individual principles of character selection and do not feel bound to the prevalence of particular characters in Taiwanese literature. As a result, there is generally little orthographic overlap between written Taiwanese in a literary context and written Taiwanese arranged in Taiyu dictionaries.

24 Alphabetic orthographies for Taiwanese and other Southern Min dialects were initially only used by missionaries for church-related publications. In the late nineteenth and early twentieth centuries, the use of either script was thus restricted to distinct social groups and literary genres. The disassociation of alphabetic writing from the missionary context was first promoted by the political activist Cai Peihuo during the Japanese period (1895-1945). Since the 1990s, the use of alphabetic writing has gone different directions within and outside the missionary context. Whereas the Presbyterian Church has switched to the use of characters, the traditional missionary romanisation system has considerably gained ground among local Taiyu groups not associated with the church. This new trend has been initiated by two organisations based in the southern port of Kaohsiung, viz. the Ko-hiong Tai-gi Lo-ma-ji Gian-sip-hoe (Kaohsiung Seminar for Church Romanisation), and the Tai-oan Lo-ma-ji Hiap-hoe (Association of Taiwanese Romanisation). The former is a rather loose, seminar-like group established in 1996. It is supported by some 600 people, mostly local school teachers, interested in the cultivation of Taiwanese and its alphabetic representation. The latter was formally registered with the Interior Ministry in 2001. It comprises about two hundred members from Taiwan and abroad. Among the members are scholars, politicians, journalists, teachers and clergy of the Presbyterian Church $^{23}$.

As indicated above, arguments in favour of or against particular scripts belong largely to socio-political debates on practical needs and cultural symbolism. The choice of a particular writing system may generally serve as an indicator for a changing national identity in colonial or post-colonial societies, as for instance in the former Soviet states Azerbaijan, Uzbekistan and Turkmenistan, where the abolition of Cyrillic writing clearly reflects a cultural trend towards de-russification after the fall of the Soviet empire $^{24}$. Similarly, sociological studies on written Taiwanese analyse the option for a particular script in ideological terms. For instance, comparing ideological convictions of Taiyu activists of the 1930s with those of the present generation, A-chin Hsiau writes: ${ }^{25}$ "Comparatively speaking, contemporary attempts to establish a Hoklo [i.e., Taiyu] script and establish Hoklo literature has achieved more than the efforts to promote writing in tai-oan-oe and hsiang-t'u literature in the Japanese colonial period. On the one hand, the promoters of the latter in the early 1930s still held a relatively intense Han cultural consciousness. Thus, all of them, with the notable exception of Ts'ai P'ei-huo (Cai Peihuo), advocated using characters to write Hoklo in order to maintain Taiwanese connections with the Chinese Mainland and Han culture. [...] By contrast, devoting themselves to the establishment of a unique Taiwanese culture, the advocates of new writing methods in the last decade have been, almost without exception, Taiwanese nationalists. Most of them do not stick to Chinese characters and freely romanise certain Hoklo morphemes. Romanisation makes it easier to write Hoklo 
and facilitates the development of Hoklo literature. The use of phonetic characters represents a historic step toward local nationalism within an old ideographic area dominated by China, including other bordering countries".

Written Taiwanese: official measures

Official language planning agencies have thus far steered off orthographic standardisation. The extent to which statements and decrees formulated by government agencies have passed over this issue is striking ${ }^{26}$. In 2002, official examinations for Taiwanese and Hakka teachers took place. The procedure of the examinations was regulated in a law that passed the legislature in late $2001^{27}$. According to the examination sample published in advance, candidate teachers were free to use characters, any romanisation system or a mixed script in the written examinations ${ }^{28}$. Standardisation of requirements for language teaching has, in other words, not been matched with orthographic specifications.

This neglect cannot be attributed to a lack of awareness, as orthographic issues have long been on the agenda of academic symposia organised by language planning institutions. A first symposium 'Issues concerning local language education' was held in June 1990 at the Academia Sinica. The event was jointly organised by seven local governments. The nine papers presented at this occasion focused on two issues exclusively: character usage and romanisation. Since then, numerous similar events have followed, and orthographic issues have continued to play an important role in the academic agenda. Also in the early 1990s, the Ministry of Education encouraged private research on local languages by awarding prizes for studies on Taiwanese and Hakka in five different categories: lexicon and orthography, grammar, teaching, traditional popular sources, and Chinese translations of studies on Taiyu ${ }^{29}$.

official measures in the field of orthographic standardisation for local languages have not gone beyond non-binding recommendations. Spelling schemes for three script types have been put forward, viz. Chinese characters, a romanisation system, and phonetic symbols. Recommendations for character usage were devised in a research project initiated by the NLC and carried out between 1995 and 1999. The project aimed at the compilation of the four-volume lexicon for Taiwanese with approximately 600 monosyllabic entries. By the spring of 2000, two volumes of the lexicon had been published $^{30}$. The publication of the final issues is listed among the NLC current projects $^{31}$. As regards orthographic standardisation, the aim of the project is described in rather vague terms. The compilers express the hope that the lexicon will "reduce difficulties in writing Southern Min"32.

Phonetic symbols for Mandarin, Taiwanese and Hakka were devised in a research project carried out at the Preparatory Institute of Linguistics, Academia Sinica, between October 1999 and September $2000^{33}$. The need for a new system was explained with the high degree of orthographic diversity in Taiwanese and Hakka sources. This was considered "inconvenient for the reader and harmful for the research on and development of Southern Min and Hakka" ${ }^{34}$. It is assumed that the project will benefit the promotion of local language education, the compilation of books in and reference works for local languages, and the development of local language literature ${ }^{35}$.

Systems for the romanisation of local languages were published in early 1998, viz. the Taiwan Language Phonetic Alphabet (TLPA) for Taiwanese and Hakka. Both systems were developed by the Linguistic Society of Taiwan (Taiwan yuwen xuehui) ${ }^{36}$. TLPA systems are recommended for the indication of character readings and not as 
substitutions for the character system. Both TLPA versions have gained acceptance in textbooks and dictionaries ${ }^{37}$.

31 Meanwhile, the NLC has announced the establishment of a database for national languages. This project is scheduled for completion in June 2004. The plan includes the publication of online databases for Mandarin and local languages, the compilation of language atlases, research on Taiwanese and Hakka grammars, the compilation of teaching materials, the compilation of a trilingual Mandarin-Taiwanese-Hakka dictionary of frequently used expressions, databases for Taiwanese and Hakka proverbs, a database of loan words used in Taiwan, and dictionaries for Austronesian languages. It is not clear what the status of the databases is. The Minister of Education is merely quoted as saying that "the work on databases for local languages (Taiwanese, Hakka, Austronesian languages) should be intensified in order to fit the needs of the new school curriculum" ${ }^{38}$. One of the "expected benefits" of the databases is the "availability for use in scientific research and education" ${ }^{39}$.

Governmental and non-governmental co-operation

The inclusion of Taiwanese and other local languages into the school curriculum marks a crucial turning point in Taiwanese language policies. For various practical reasons, the decision to make learning a local language compulsory for primary school students entails a number of related language-planning measures. Most importantly, Taiyu textbooks need to be compiled. Textbook compilation is for obvious reasons receiving increasing attention of academics and language revivalists: they are the only source of written Taiwanese with a substantial readership outside particular interest groups. Thus far, textbooks for various levels have been published, viz. for elementary and secondary school students ${ }^{40}$. School textbooks are typically compiled by municipal or county governments, in co-operation with academics and local language revivalists. Textbooks jointly compiled by groups of authors generally gain more acceptance than those published by individuals.

Textbook compilation has thus far not come along with orthographic standardisation. This has led to the awkward situation that primary school students at different schools learn different forms of written Taiwanese, depending on the policy of the respective school authority and the non-governmental advisors. Future research needs to examine the way central and local government agencies, universities and private interest groups interact in implementing language education reforms. For the purpose of this present study it is sufficient to point out that the co-operation of nongovernmental and governmental language planners goes beyond the compilation of textbooks. Academics and members of private Taiyu circles are furthermore recruited for the organisation of preparatory courses for Taiyu school teachers and the development of curricula.

Is Taiwan on the way to becoming a multilinguistic society in which all languages are equal? I argue that despite the recent promotion of local languages Mandarin will remain more equal than other languages. The main reason is that language planning measures taken so far are largely of symbolic value, and will arguably not lead to substantial changes in Taiwan's linguistic hierarchy.

In language planning theory, determining the written standard for a language relates to the field of corpus planning. Other aspects of corpus planning are "elaboration of phonological, grammatical, and lexical norms for a standard language variety" ${ }^{41}$. Orthographic standardisation as a part of corpus planning is unlikely to succeed if 
implemented independently from other fields of language planning, such as status planning. Status planning relates to the sociocultural and political status of languages, for example "the status of a language as a medium of school education to various specialised functions, such as those of a working language to be used in a state bureaucracy, in juridical affairs, or as an official state language" ${ }^{42}$. In other words, the success of particular corpus planning measures ultimately depends on whether these measures occur within the context of status planning, and vice versa. As Haarmann puts it, "the elaboration of a written standard for a hitherto unwritten language requires the planning of social functions in which it can be used"43. A similar stance is formulated by Gadelii, who holds that "well-intentioned bilingual programmes and similar actions only have symbolic value in the long run if the languages involved are not recognized in other formal contexts" ${ }^{44}$.

Taking these aspects into account, it is obvious that recent language planning measures with regard to Taiyu and other local languages still lack comprehensiveness. Within the field of corpus planning, the main focus has been orthographic standardisation. Other aspects, like standardisation of pronunciation and grammar, have largely been ignored. More importantly, there are also crucial missing links between the different fields of language planning. Despite the introduction of nativist education, Taiyu continues to play a marginal role in education and in the media. In Shuanfan Huang's words, "local languages have to contend not only with Mandarin, the official language, for breathing space, but also with international languages [...] for survival" ${ }^{45}$. The role of Taiwanese in the school curriculum is thus not a sufficient formal context that could contribute to the implementation of a Taiwanese orthography. Stated conversely, the fact that the introduction of mother tongue education was not accompanied by orthographic standardisation is in line with the modest position of local language education in the school curriculum.

The MOE's cautious approach to orthographic regulation is apparently not without reason. Official language planning institutions still suffer from their past sins. Bitter reminiscences about the government's oppression of local languages before the $1980 \mathrm{~s}$ now clearly undermine what Cooper calls "the coercive power of the state to enforce language-planning decisions" ${ }^{\prime 4}$. In other words, the governmental authority of the MOE and its NLC is in fact counterproductive when it comes to acceptance in Taiyu circles.

\section{NOTES}

1. Shuanfan Huang, Yuyan, shehui yu zuqun yishi: Taiwan yuyan shehuixue de yanjiu (Language, society and ethnic identity: A sociolinguistic study on Taiwan), Taipei, Crane, 1993.

2. Paul Jen-kuei Li, "Formosan Languages: The State of the Art", in David Blundell (ed.), Austronesian Taiwan: Linguistics, History, Ethnology, Prehistory, Berkeley, Taipei, Phoebe A. Hearst Museum of Anthropology, Shung Ye Museum of Formosan Aborigines, 2000, pp. 45-67. 
3. China Handbook 1951, Taipei, China Publishing Co., 1951.

4. Taiwan Yearbook 2003, online at http://www.gio.gov.tw/taiwan-website/5-gp/ yearbook/chpt02.htm, accessed June 10th 2004.

5. Karl-Eugen Feifel, Language Attitudes in Taiwan: A Social Evaluation of Language in Social Change, Taipei, Crane, 1994, p. 72.

6. Robert L. Cheng, "Language Unification in Taiwan: Present and Future", in Murray A. Rubinstein (ed.), The Other Taiwan: 1945 to the Present, Armonk, Sharpe, p. 361.

7. Feifel, Language Attitudes in Taiwan, op. cit., p. 72.

8. Huang, Yuyan, shehui yu zuqun yishi, op. cit., p. 119.

9. Marinus E. Van den Berg, Language Planning and Language Use in Taiwan: A Study of Language Choice Behavior in Public Settings, Taipei, Crane, 1986, p. 184.

10. Huang, Yuyan, shehui yu zuqun yishi, op. cit., p. 146

11. Ibid.

12. Yang Chaur-shiang, "National Education Development and Reform for the New Millennium", 1999, online at http://www.edu.tw/minister/case/report4.htm, accessed April 2nd 2002.

13. Ministry of Education (MOE), “Explanation Why the 'Language Equality Law' Will Be Drafted by the Council for Cultural Affairs", 2004, online at http://www.edu.tw, accessed June 10th 2004.

14. Robert L. Cooper, Language Planning and Social Change, Cambridge, Cambridge University Press, 1989, p. 183.

15. A-chin Hsiau, Contemporary Taiwanese Cultural Nationalism, London, Routledge, 2000, p. 74 .

16. Ibid.

17. Ibid, p. 137.

18. "Shijie Taiwan Muyu Lianmeng" (Global Coalition for Taiwanese Languages), 2004, online at http://203.64.42.21/TG/BGLB, accessed June 10th 2004.

19. For details, see Henning Klöter, Written Taiwanese, Ph.D. dissertation, Leiden University, 2003.

20. Hsiau, Contemporary Taiwanese Cultural Nationalism, op. cit., p. 136; Lin Yangmin, Taiyu wenxue yundongshi lun (The History of the Taiyu Literature Movement), Taipei, Qianwei, 1996, p. $19 f$.

21. For a more comprehensive introduction to recent Taiyu literature, refer to Zhang Chunhuang et al., Tai-gi bun-hak kai-lun (An Introduction to Taiyu literature), Taipei, Qianwei, 2001.

22. For example, Dong Zhongsi, Taiwan Minnanyu cidian (A Dictionary of Southern Min of Taiwan), Taipei, Wu Nan Tushu Chuban, 2001; Qiu Wenxi and Chen Xianguo, Shiyong huayu taiyu duizhao dian (A Practical Comparative Mandarin-Taiwanese Dictionary), Taipei, Zhangshu, 1996; Shiyong Taiwan yandian (A Practical Dictionary of Taiwanese Sayings), Taipei, Zhangshu, 1999; Gô Kok-An, Taiyu siyong hanzi ziyuan / The Origins of Hanji Usage in Taiwanese: The Advanced Learner's Dictionary for Writing Taiwanese, Taipei, privately published, 1998; Wu Shouli, Zonghe Taiwan Minnanyu jiben zidian chugao (A First Draft of a Basic Dictionary for the Southern Min Dialect of Taiwan), Taipei, Wen Shi Zhe, 1987; Guo-Tai duizhao huoyong cidian: cixing fenxi, xiang zhu Xia Zhang Quan yin (shang, xia ce) (A Comparative Mandarin-Taiwanese Dictionary For Practical Use, With Detailed Annotations of Xiamen, Zhangzhou, and Quanzhou Sounds), 2 Vols., Taipei, Yuanliu, 2000.

23. Klöter, Written Taiwanese, op. cit., p. $214 \mathrm{ff}$. 
24. Jacob Landau and Barbara Kellner-Heinkele, Politics of Language in the Ex-Soviet Muslim States: Azerbaijan, Uzbekistan, Kazakhstan, Kyrgyzstan, Turkmenistan, and Tajikistan, Ann Arbor, University of Michigan Press, 2000.

25. Hsiau, Contemporary Taiwanese Cultural Nationalism, op. cit., p. 139.

26. For example, in NLC, "Xiangtu yuyan jiaoxue xiankuang yu weilai yuwen jiaoxue zhi fazhan" (The Present Situation of Local Language Education and the Future Development of Language Teaching), Yuwen jianxun / Language Education Newsletter 3 (May), 2000, online at http://www.edu.tw/mandr/ publish/jian/03/p1.htm, accessed April 2nd 2002; DEJ, "How should the Ministry of Education implement local language education?", 2001, online at http://teach.eje.edu.tw, accessed June 28th 2001.

27. MOE, “Jiaoyubu xinwen gao: Minnanyu, Kejiayu zhiyuan jiaoxue renyuan jiange gongzuo jijiang banli" (MOE News Release: Assessments of Personnel Assisting the Teaching of Southern Min and Hakka About to Take Place), 2002, online at http:// www.edu.tw/secretary/importance/901220-2.htm, accessed April 2nd 2002.

28. MOE, "Jiaoyubu xinwen gao: Jiaoyubu gongbu xiangtu yuyan jiaoxue zhiyuan renyuan jiange bishi, koushi shijian ji tixing" (MOE News Release: MOE Announces Time and Question Types for Written and Oral Tests for Personnel Assisting the Teaching of Local Languages), 2002, online at http://teach.eje.edu.tw/data/ sun/ 20022251056/910222.htm?paperid=2945, accessed April 2nd 2002.

29. NLC, Minnanyu zihui (yi) (A Lexicon of Southern Min, Part I), Taipei, 1998.

30. NLC, Fangyin fuhao xitong (System of Phonetic Symbols for Dialects), 1998, online at http://www.edu.tw/mandr/bbs/1-4-7.htm, accessed February 2nd 2003; Minnanyu zihui (er) (A Lexicon of Southern Min, Part II), Taipei, 1999.

31. NLC, "Guojia yuwen ziliaoku jiangou jihua" (The Plan to Set Up a Database for National Languages), 2001, online at http://www.edu.tw/mandr/business/kuhdbf.htm, accessed April 2nd 2002.

32. NLC, Minnanyu zihui (yi), op. cit., p. 1.

33. NLC, "Min Ke yu zhuyin fuhao zhuan'an yanjiu" (Special Aspects of the Research Into Phonetic Symbols for Southern Min and Hakka), 2000, online at http:// www.edu.tw/mandr/news/xtxj.htm, accessed April 2nd 2002.

34. Ibid.

35. Ibid.

36. Dong Zhongsi, “Guanyu 'Taiwan yuyin yinbiao fang'an”' [On 'TLPA'], in Dong Zhongsi (ed.), 'Taiwan Minnanyu gailun' jiangshou ziliao huibian (A Compilation of Teaching Materials for "An Introduction to the Southern Min Language of Taiwan"), Taipei, Taiwan yuwen xuehui, 1996, pp. 27-69.

37. For example, Dong, Taiwan Minnanyu cidian, op. cit.; Qiu Wenxi and Chen Xianguo, Shiyong huayu taiyu duizhao dian, shiyong Taiwan yandian, op. cit.

38. NLC, "Guojia yuwen ziliaoku jiangou jihua", op. cit.

39. Ibid.

40. For an overview, see Klöter, Written Taiwanese, op. cit.

41. Harald Haarmann, "Language Planning in the Light of a General Theory of Language: A Methodological Framework", International Journal of the Sociology of Language, No. 86, 1990, p. $106 \mathrm{ff}$.

42. Ibid.

43. Ibid.

44. Karl Erland Gadelii, Language Planning: Theory and Practice. Evaluation of Language Planning Cases Worldwide, Paris, Unesco, 1999, p. 24. 
45. Shuanfan Huang, "Language, Identity and Conflict: A Taiwanese Study", International Journal of the Sociology of Language, No. 143, 2000, pp. 139-149.

46. Cooper, Language Planning and Social Change, op. cit., p. 77.

\section{ABSTRACTS}

The revival of the Taiwanese language (Taiyu) in the past two decades is a significant about-face, after the restrictive measures that the government has adopted for local languages in the past. This article compares the treatment of Taiyu by official language planning agencies during the Kuomintang) KMT and Democratic Progressive Party (DPP) eras. It focuses on the debates on the creation of a written norm for Taiyu. Attention is also given to the activities of nongovernmental language revival groups and the co-operation between official and unofficial language planners in the implementation of recent language reforms. 